\title{
Study of mandibular thickness in dentulous and edentulous mandibles
}

\author{
Anand Jagannath Reddy ${ }^{1}$, Rakhi Milind More ${ }^{2, *}$ \\ ${ }^{\mathbf{1}}$ Assistant Professor, Dept. of Anatomy, MIMSR Medical College, Latur, Maharashtra, ${ }^{2}$ Associate Professor, Dept. of Anatomy, \\ K. J. Somaiya Medical College, Mumbai, Maharashtra, India \\ *Corresponding Author: Rakhi Milind More \\ Email: drrakhimmore@gmail.com
}

Received: $11^{\text {th }}$ May, 2018

Accepted: $28^{\text {th }}$ May, 2018

\begin{abstract}
There are several methods of reconstruction for lower human jaw, but the most common and safest is using plates and screws. The size of the lower jaw bone varies from person to person, therefore plates and screws are available in different sizes. ${ }^{1} \mathrm{~A}$ critical buccal bone thickness of $2 \mathrm{~mm}$ is recommended to prevent vertical resorption. A minimum bone thickness of $6 \mathrm{~mm}$ would be required for successful placement of a standard-sized \pm 4 -mm-diameter implant. ${ }^{2}$ In the present study Mandibular Body Thickness (MBT) was studied in 110 dry mandibles to evaluate the ideal length of dental implants used during the corrective procedures on the mandibular alveolar process. All the mandibles in our study had adequate bone thickness needed for implant placement without traumatizing the sublingual artery.
\end{abstract}

Keywords: Mandible, Symphysis menti, Premolar, Molar, Reconstruction, Maxillofacial surgery.

\section{Introduction}

The mandible is one of the most commonly fractured structures during facial trauma. ${ }^{3}$ Rigid fixation, which typically involves open reduction and internal fixation of the fractured fragments with titanium plates, is a commonly used technique for treating these mandibular fractures. ${ }^{4-7}$ The titanium plates buttress the mandibular fragments and can bear mild functional load during healing. Rigid fixation techniques often involve the securing of a strength plate along the inferior border of the mandible with at least 2 bicortical screws on either side of the fracture. ${ }^{7-9}$ For bicortical screw placement, each screw should engage both the buccal and lingual cortices of the bone. Hence, choosing a screw length that protrudes entirely through the mandible is a standard technique. ${ }^{10}$

\section{Aims}

1. To measure thicknesses in clinical landmark areas of the dentate \& edentate mandibles.

2. To evaluate the ideal length of dental implants used during the corrective procedures on the mandibular alveolar process.

\section{Materials and Methods}

Measurements were made on one hundred and ten dry, macerated adult human mandibles of unknown sex. All mandibles were obtained from Bharati Vidyapeeth Deemed University Medical College, Pune and other Medical Colleges in Maharashtra, with prior permission of the concerned authorities. The mandibles were apparently normal, without any structural deformity. Dentulous (teeth $\geq 14 ; \mathrm{n}=98$ ) and Edentulous (without any teeth; $n=12$ ) mandibles were included for this study. Parameters were measured bilaterally wherever required.

\section{Equipment}

1. Geometrical protractor with marking up to $180^{\circ}$

2. Digital vernier calliper with $0.01 \mathrm{~mm}$. precision

3. Measuring scale having marking up to $150 \mathrm{~mm}$

4. Flexible measuring tape

5. Marker pen and pencil

6. Plain white papers

Mandibular Body Thickness (MBT): Maximum thickness of body of mandible measured at various level of body of mandible in vertical axis;

1. At the level of Symphysis Menti (SM) (Fig. 1)

2. Between two Premolars (PM) (Fig. 2)

3. At the level of middle of second molar, if third molar is erupted (M) (Fig. 3)

4. Between two molar, if third molar is not erupted.

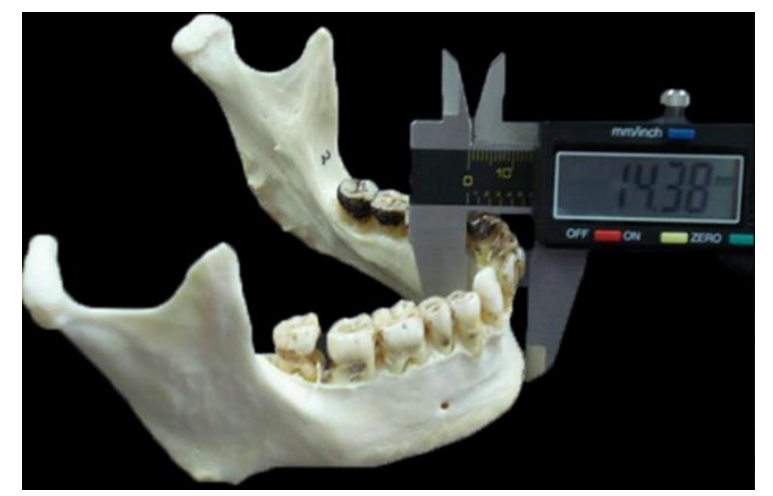

Fig. 1: MBT-SM (Mandibular body thickness at Symphysis menti) 


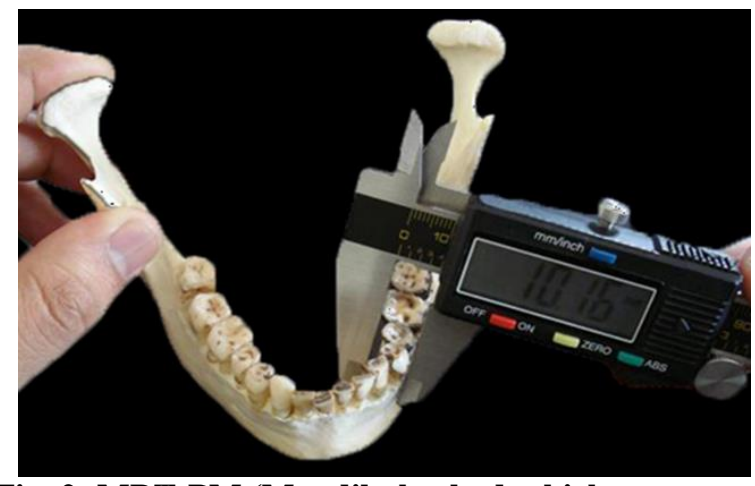

Fig. 2: MBT-PM (Mandibular body thickness at Premolar teeth)

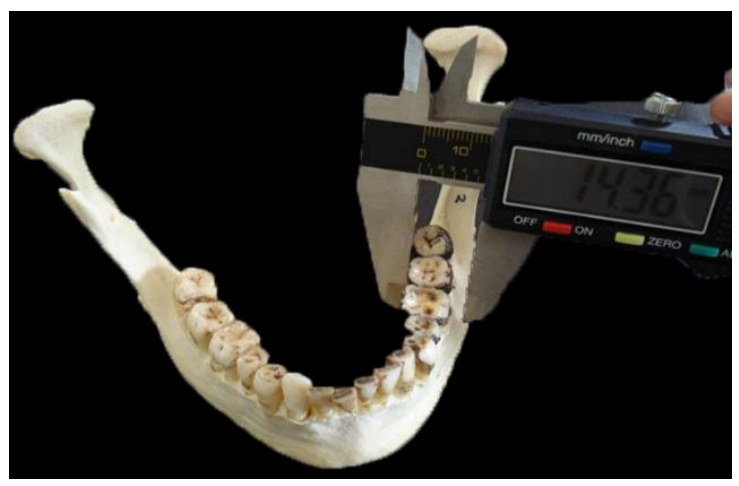

Fig. 3: MBT-M: Mandibular body thickness at molar teeth

\section{Observations}

Table 1: Measurements (in mm) of Mandibular Body Thickness (MBT) at various anatomical landmarks in Dentulous Mandibles. D (n=98)

\begin{tabular}{|c|c|c|c|c|c|c|c|c|}
\hline & & & Maximum & Minimum & Mean \pm SD & Mean \pm SD $(\mathrm{R}+\mathrm{L})$ & P value & $Z$ value \\
\hline \multirow[t]{5}{*}{ MBT } & SM & & 27.10 & 10.06 & $14.17 \pm 2.31$ & & & \\
\hline & \multirow[t]{2}{*}{ PM } & $\mathrm{R}$ & 18.40 & 7.44 & $11.68 \pm 2.04$ & \multirow[t]{2}{*}{$12.80 \pm 2.08$} & \multirow[t]{2}{*}{$4.92939 \mathrm{E}-14^{*}$} & \multirow[t]{2}{*}{7.533} \\
\hline & & $\mathrm{L}$ & 18.47 & 7.96 & $13.99 \pm 2.25$ & & & \\
\hline & \multirow[t]{2}{*}{$\mathrm{M}$} & $\mathrm{R}$ & 18.16 & 7.32 & $11.34 \pm 1.77$ & \multirow[t]{2}{*}{$12.56 \pm 2.01$} & \multirow[t]{2}{*}{$0 *$} & \multirow[t]{2}{*}{8.5783} \\
\hline & & $\mathrm{L}$ & 18.12 & 9.25 & $13.83 \pm 2.27$ & & & \\
\hline
\end{tabular}

Statistically highly significant** $(\mathrm{P}<0.001)$

Table 2: Measurements (in mm) of Mandibular Body Thickness (MBT) at various anatomical landmarks in Edentulous Mandibles, ED $(\mathbf{n}=12)$

\begin{tabular}{|c|c|c|c|c|c|c|c|}
\hline & & & Maximum & Minimum & Mean \pm SD & $\begin{array}{c}\text { Mean } \pm \text { SD } \\
(\mathbf{R}+\mathbf{L})\end{array}$ & P value \\
\hline \multirow{3}{*}{ MBT } & \multicolumn{2}{|c|}{ SM } & 15.01 & 10.10 & $13.41 \pm 1.61$ & & \\
\cline { 2 - 7 } & \multirow{2}{*}{ PM } & $\mathrm{R}$ & 16.78 & 9.88 & $13.47 \pm 2.01$ & $12.78 \pm 2.02$ & $0.0345^{*}$ \\
\cline { 2 - 8 } & & $\mathrm{L}$ & 15.36 & 9.89 & $12.09 \pm 2.02$ & & \\
\cline { 2 - 8 } & \multirow{2}{*}{$\mathrm{M}$} & $\mathrm{R}$ & 18.90 & 12.42 & $15.90 \pm 2.21$ & $15.64 \pm 2.35$ & 0.1418 \\
\cline { 2 - 7 } & & $\mathrm{L}$ & 17.81 & 11.64 & $15.38 \pm 2.49$ & & \\
\hline
\end{tabular}

Statistically significant $*(\mathrm{P}<0.05)$

Bar diagram 1: Measurements (in mm) of Mandibular Body Thickness (MBT) at various anatomical landmarks in Dentulous (D) and Edentulous (ED) Mandibles

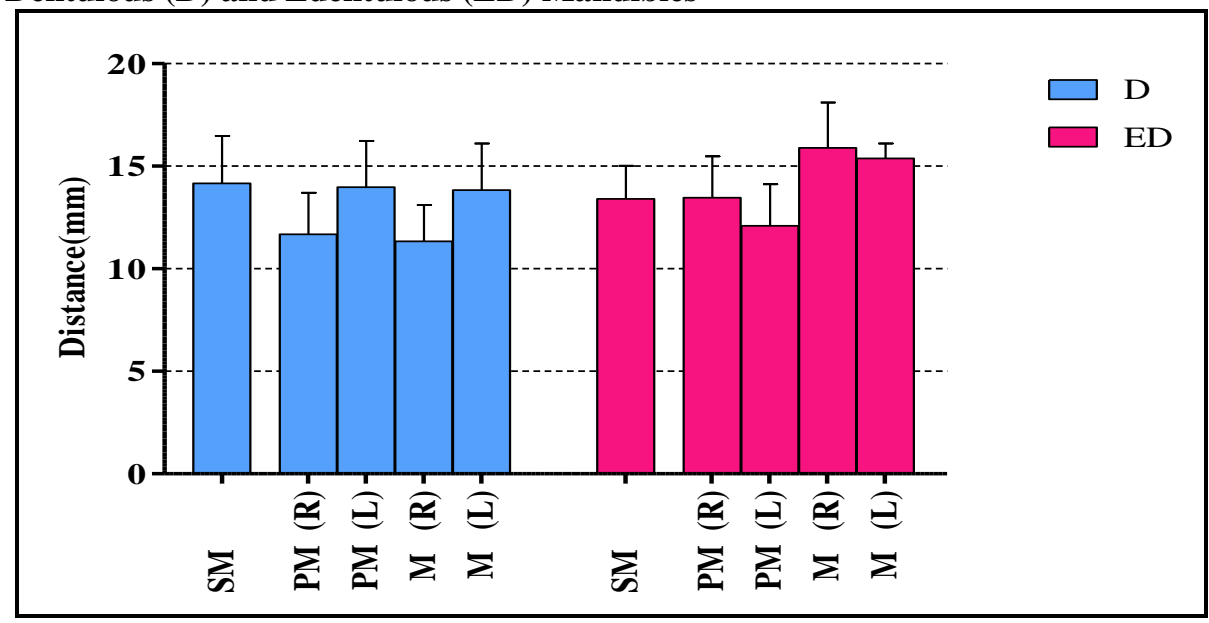

Abbreviations used in Tables 1 and 2 and Bar diagram 1 Symphysis Menti (SM), Premolar (PM) and Molar (M) teeth on Right (R) and Left (L) Dentulous (D) and Edentulous (ED) 


\section{Discussion}

In the present study mean values of Mandibular Body Thickness (MBT);

At the level of Symphysis Menti (SM) in-

1. Dentulous group is $14.17 \mathrm{~mm}$ (maximum 27.01, minimum 10.06).

2. Edentulous group is $13.41 \mathrm{~mm}$ (maximum 15.01, minimum 10.10).

At the level of Premolar Teeth (PM) in

1. Dentulous group on right side is $11.68 \mathrm{~mm}$ (maximum 18.40mm, minimum $7.44 \mathrm{~mm}$ ) and on left side is $13.99 \mathrm{~mm}$ (maximum $18.47 \mathrm{~mm}$, minimum $7.96 \mathrm{~mm}$ ). Statistically these two values differ significantly on both sides. $(\mathrm{P}<0.001)$ (Table 1)
2. Edentulous group on right side is $13.47 \mathrm{~mm}$ (maximum $16.78 \mathrm{~mm}$, minimum $9.88 \mathrm{~mm}$ ) and on left side is $12.09 \mathrm{~mm}$ (maximum $15.36 \mathrm{~mm}$, minimum $9.89 \mathrm{~mm}$ ) These two values are statistically highly significant. $(\mathrm{P}<0.05)$ (Table 2$)$

At the level of Molar teeth (M)

1. Dentulous group on right side is $11.34 \mathrm{~mm}$ (maximum $18.16 \mathrm{~mm}$, minimum $7.32 \mathrm{~mm}$ ) $\mathrm{v}$ and on left side is $13.83 \mathrm{~mm}$ (maximum $18.12 \mathrm{~mm}$, minimum $9.25 \mathrm{~mm}$ ). Statistically these two values are significant. $(\mathrm{P}<0.001)$ (Table no. 1$)$

2. Edentulous group on right side is $15.90 \mathrm{~mm}$ (maximum $18.90 \mathrm{~mm}$, minimum $12.42 \mathrm{~mm}$ ) and on left side is $15.38 \mathrm{~mm}$ (maximum $17.81 \mathrm{~mm}$, minimum $11.64 \mathrm{~mm}$ ). Statistically these two values are insignificant.

Table 3: Comparison between mean values of Mandibular body thickness at the level of molar teeth of present study in dentulous mandibles with the available data

\begin{tabular}{|c|c|c|c|c|c|c|}
\hline \multirow{2}{*}{$\begin{array}{c}\text { Present } \\
\text { study* }(\mathbf{m m})\end{array}$} & \multicolumn{4}{|c|}{ Eugene Giles (mm) } & \multirow{2}{*}{\multicolumn{2}{|c|}{ N. D. Mandke (mm) }} \\
\hline & \multicolumn{2}{|c|}{ White population } & \multicolumn{2}{|c|}{ Negro population } & & \\
\hline \multirow[t]{2}{*}{12.56} & $\mathrm{M}$ & $\mathrm{F}$ & $\mathrm{M}$ & $\mathrm{F}$ & $\mathrm{M}$ & $\mathrm{F}$ \\
\hline & 14.58 & 14.10 & 15.12 & 14.74 & 15.18 & 14.5 \\
\hline
\end{tabular}

* Sex not specified, M - Male, F - Female

Very few studies have been done on total mandibular body thickness. Eugene Giles ${ }^{11}$ measured body thickness at the level of second molar parallel to vertical axis of body to determine the sex in White and
Negro population. Values of Body thickness at molar tooth in dentulous group of present study are smaller than findings of Eugene Giles ${ }^{11}$ and N. D. Mandke. ${ }^{12}$ Table 3

Table 4: Comparison between mean values of mandibular body thickness (in mm) at the level of symphysis menti of present study in dentulous mandibles with the available data

\begin{tabular}{|c|c|c|}
\hline Present study* (mm) & Narlin B. Beaty and Thomas T Le (mm) \\
\hline 14.17 & M & F \\
\cline { 2 - 3 } & 14.03 & 13.21 \\
\hline
\end{tabular}

*Sex not specified, M - Male, F - Female

Narlin B. Beaty and Thomas T Le ${ }^{13}$ measured total mandibular body thickness at seven different surgically useful sites. Values of body thickness at symphysis menti in dentulous group of present study $(14.17 \mathrm{~mm})$ coincides with their findings. Mean mandibular thickness at the symphysis menti in their studies were $14.03 \mathrm{~mm}$ in males and $13.21 \mathrm{~mm}$ in females. (Table 4 )

In Indian population, body thickness was measured by $\mathrm{N}$. Bapna, ${ }^{14}$ but they have not mentioned the level of measurement of body thickness. Value of their study is $16 \mathrm{~mm}$ which is far greater than present study in both groups. N. D. Mandke ${ }^{12}$ measured body thickness at the level of molar teeth (male $15.18 \mathrm{~mm}$, female $14.5 \mathrm{~mm}$ ).

Many experienced mandibular surgeons have developed an intimate knowledge of mandibular thicknesses and necessary screw sizes through clinical practice and hence use a depth gauge infrequently. In a study conducted by Narlin B et $\mathrm{al}^{13}$ the authors have achieved good clinical outcomes in more than 300 mandibular fracture fixations, with the estimation of bicortical screw size primarily through prior knowledge of screw size at the fracture location and the reservation of the depth gauge only for instances that involve aberrations of normal intracortical thickness (eg, oblique fractures or lag screwing). Although surgeons may choose to estimate bicortical screw size through a number of methods (eg, anatomical averages, experience based estimates, preoperative CT measurements, metered drill bits, or depth gauge), ultimately, sound plating techniques and ample mandibular bone stock for screw engagement are much more important factors in proper fracture fixation than the method of screw size estimation. Future studies that describe the accuracy of alternative screw size estimation techniques relative to speed of surgery and long-term fixation outcomes may be warranted.

Knowledge of mandibular thickness measurements can be used as a practical reference for a number of applications, including mandibular fracture repair, mandibular reconstruction, and the understanding of mandibular anatomy in general. 


\section{Conclusion}

In the present study Mandibular Body Thickness (MBT) was studied in clinical landmark areas of the 110 dry dentate \& edentate human mandibles to evaluate the ideal length of dental implants used during the corrective procedures on the mandibular alveolar process. All the mandibles in our study had adequate bone thickness needed for implant placement without traumatizing the sublingual artery. Quantitative record of the mandibular thickness was prepared that may be of interest to the anatomists and orthodontists.

\section{References}

1. Abbas A. T., Reconstruction skeleton for the lower human jaw using CAD/CAM/CAE, Journal of King Saud University - Engineering Sciences. 2012;25(2):159-164.

2. Gakonyo J. Arterial blood supply variation in the anterior midline mandible: Significance to dental implantology. International journal of Implant Dentistry. 2015;1(1):24 .

3. Longoni S, Sartori M, Braun M, Bravetti P, Lapi A, Baldoni M. Lingual vascular canals of the mandible: the risk of bleeding complications during implant procedures. Implant Dent. 2007;16(2):131-138. doi: 10.1097/ID.0b013e31805009d5.

4. Tepper G, Hofschneider UB, Gahleitner A, Ulm C. Computed tomographic diagnosis and localization of bone canals in the mandibular interforaminal region for prevention of bleeding complications during implant surgery. Int J Oral Maxillofac Implants. 2001;16:68-72.

5. Liang X, Jacobs R, Lambrichts I. An assessment on spiral CT scan of the superior and inferior genial spinal foramina and canals. Surg Radiol Anat. 2006;28:98-104. doi: 10.1007/s00276-005-0055-y.

6. Niamtu J., 3rd Near-fatal airway obstruction after routine implant placement. Oral Surg Oral Med Oral Pathol Oral Radiol Endod. 2001;92:597-600. doi:10.1067/moe.2001.116503.
7. Flanagan D. Important arterial supply of the mandible, control of an arterial hemorrhage, and report of a hemorrhagic incident. J Oral Implantol. 2003;29:165173. doi: $10.1563 / 1548-$

1336(2003)029<0165:IASOTM>2.3.CO;2.

8. Loukas M, Kinsella CR, Jr, Kapos T, Tubbs RS, Ramachandra S. Anatomical variation in arterial supply of the mandible with special regard to implant placement. Int J Oral Maxillofac Surg. 2008;37:367-371. doi: 10.1016/j.ijom.2007.11.007.

9. Kalpidis CD, Setayesh RM. Hemorrhaging associated with endosseous implant placement in the anterior mandible: a review of the literature. J Periodontol. 2004;75:631-645. doi: 10.1902/jop.2004.75.5.631.

10. McDonnell D, Reza Nouri M, Todd ME. The mandibular lingual foramen: a consistent arterial foramen in the middle of the mandible. J Anat. 1994;184:363-369.

11. Eugene Giles - Sex determination by discriminant function analysis of the human mandible. American Journal of Physical Anthropology. 1964;22(2);129-135.

12. N. D. Mandke - Anthropometric study of human mandible in Vidarbha region (1989). Dissertation submitted to Nagpur University.

13. Narlin B. Beaty, Thomas T. Le - Mandibular thickness measurements in young dentate adults. Archives of otolaryngology - Head and Neck Surgery. 2009;135(9);920-923.

14. N. Bapna, L. Mehata, N.K. Harneja - Metrical features of mandible- Rajasthan zone. Journal of Anatomical Society of India. (1976).

How to cite this article: Reddy A. J, More R. M. Study of mandibular thickness in dentulous and edentulous mandibles. Indian $\mathrm{J}$ Clin Anat Physiol. 2018;5(4):457-460. 